\title{
Clinical and sociodemographic features of children and adolescents with specific learning disorder (SLD)
}

\author{
Zeynep Goker ${ }^{1}$, Ozden Sukran Uneri ${ }^{1}$, Esra Guney ${ }^{2}$, Gulser Dinc ${ }^{1}$, Ozlem Hekim-Bozkurt ${ }^{1}$ \\ ${ }^{1}$ Child Psychiatry, Ankara Pediatric Hematology Oncology Training and Research Hospital, Ankara, Turkey \\ ${ }^{2}$ Child Psychiatry, Gazi University Medical School, Ankara, Turkey
}

\section{Email address:}

zeynepgoker@hotmail.com (Z. Goker), ozdenuneri@yahoo.com (O. S. Uneri), dresraguney@gmail.com (E. Guney), gulserdinc@yahoo.com (G. Dinc), hekimozlem@yahoo.com (O. Hekim-Bozkurt)

\section{To cite this article:}

Zeynep Goker, Ozden Sukran Uneri, Esra Guney, Gulser Dinc, Ozlem Hekim-Bozkurt. Clinical and Sociodemographic Features of Children and Adolescents with Specific Learning Disorder (SLD). American Journal of Psychiatry and Neuroscience. Vol. 2, No. 6, 2014, pp. 90-95. doi: $10.11648 /$ j.ajpn.20140206.12

\begin{abstract}
Background: To evaluate of child or adolescent with specific learning disorder (SLD) was aimed and if there are any distinctive patterns of Weschler Intelligence Scale for Children-Revised (WISC-R) performance, accepted as a determiner of cognitive functioning, was explored. Method: Over a-year period of data related to SLD diagnosed with DSM-IV-TR criteria was reviewed. Socio-demographic and clinical features were analyzed by using SPSS 17.0 program. Results: In a year of period, $716 / 25,013$ had any type of SLD (2.9\%). Mean age was $8.9 \pm 1.7$ years with $65.4 \%$ of boys and $87.2 \%$ of under 12 -year-old group. The majority of SLD subtype was "reading disorder (71.6\%)". There was no difference of SLD subtypes either distribution between sexes or age groups. Neither verbal IQ nor performance IQ was significantly different amongst four subtypes of SLD as well as total IQ scores. Also any relation was not found between subtypes of SLD and sexes or age groups in the distribution of WISC-R scores terms. Also there were not any consistent discrepancy patterns (VIQ $>$ PIQ or PIQ $>$ VIQ) in SLD subtypes. The presence of "reading disorder" was found significantly related with attention deficit-hyperactivity (ADHD) comorbidity $\left(\mathrm{X}^{2}=7.006, \mathrm{p}=0.008\right)$. Conclusions and Recommendations: ADHD is one of neurodevelopmental disorders and its presence could very well affect the SLD or vice versa. Further research would make clear both the relation between ADHD and SLD. Alongside cognitive measurements by using a number of intelligence scales would be enlightening in SLD field.
\end{abstract}

Keywords: Specific Learning Disorder, Children, Adolescents, DSM-IV-TR, ADHD, Comorbidity

\section{Introduction}

Specific Learning Disorder (SLD) is one of the most considerable disabilities, representing itself as a cognitive dysfunction of childhood problematic that affects around $2-10 \%$ of the school-age population $[1,2]$. This category points out that these are brain-based processes that interfere with learning and there is some evidence that SLD is one of the heterogeneous disorders, and seems to be persistent and has inherent characteristics [3]. Though our understanding of the physiological basis of it is still unclear, it is thought that learning disability could be treatable and curable through pharmacology or appropriate learning paradigms such as specific mechanistic-based teaching strategies [4]. Moreover, there is thought that the early treatment of the learning disorders could very well reduce to develop any mental disorders in children's adulthood period [5].

We examined retrospectively the data collected in Ankara
Pediatric Hematology Oncology Training and Research Hospital Child Psychiatry Department from May 2012 to May 2013 to detect and evaluate of child or adolescent with SLD.

\section{Method}

All data recorded over a-year period (May 2012-May 2013) in Child Psychiatry Department were reviewed. Data of children (under 12-year-old group) or adolescents (12-year-old and above group) diagnosed with SLD according to the American Psychiatric Association, Diagnostic and Statiscal Manual of Mental Disorders' DSM-IV-TR criteria [6] were analyzed. Weschler Intelligence Scale for Children-Revised (WISC-R) test was carried out to evaluate the cognitive functions. Clinical and socio-demographic features of them were entered SPSS 17.0 program (Chicago Inc., 2008). Statistical analysis: Chi-square test and Fisher's exact test were used to analyze distribution of SLD subtypes 
amongst gender and age groups (between and within). One-way ANOVA test was used to determine any relation between IQ scores and SLD subtypes, and Univariate variance analysis was carried out to find any association between SLD subtypes and sex or age groups. $\mathrm{p}<0.05$ was accepted as statistically significant.

\section{Results}

We found the record of total 716 children or adolescents within the total 25,013 admission over in a year-period $(2.9 \%)$. In sampling, $65.4 \%(n=468)$ of them were boys and $87.2 \%$ of them were under 12-year-old group. Mean age of patients was $8.9 \pm 1.7$ years of age ( 6 to 14 years). Boys/girls ratio was 1.8:1 and children/adolescents ratio was 6.8:1.

SLD subtypes distribution was the following: $71.6 \%$ $(\mathrm{n}=513)$ of all patients had "reading disorder", $12.4 \%$ of all $(n=89)$ had "disorder of written expression", $10.9 \%$ of all $(n=78)$ had "learning disorder not otherwise specified (NOS)" and $5 \%$ of all $(n=36)$ had "mathematics disorder".

Turning to the comorbidity rates, $58.5 \%(n=419)$ of all had no any psychiatric disorders while $16.1 \%(n=115)$ of children or adolescents had borderline intellectual functioning (full scale IQ scores: $70-79), 14.4 \%(n=103)$ of all had attention deficit hyperactivity disorder (ADHD), and 5\% $(n=36)$ of all had any of anxiety disorders (table 1). WISC-R test results were reached to $89.5 \%(n=641)$ of all patients.

There was no difference of SLD subtypes distribution between boys and girls $(\mathrm{X} 2=4.941, \mathrm{p}=0.176)$. Similarly, there was not found any difference between SLD subtypes and age groups $(\mathrm{X} 2=0.662, \mathrm{p}=0.882)$. Neither mean verbal IQ scores nor mean performance IQ scores obtained from WISC-R were significantly different amongst four subtypes of SLD $(\mathrm{F}=2.401, \mathrm{p}=0.067$ for verbal IQ; $\mathrm{F}=1.604, \mathrm{p}=0.187$ for performance IQ, respectively) as well as mean total IQ scores $(\mathrm{F}=1.534, \mathrm{p}=0.205)$ (table 2).

There were also no any relation between IQ subtypes' distribution within the subtypes of SLD and $\operatorname{sex}(\mathrm{F}=2.151$, $p=0.093$ for verbal IQ; $F=0.426, p=0.734$ for performance IQ; $\mathrm{F}=0.203, \mathrm{p}=1.534$ for full scale IQ). Similarly, the distribution of all IQ subtypes scores amongst age groups $(\mathrm{F}=1.945$, $\mathrm{p}=0.144$ for verbal IQ; $F=0.251, p=0.778$ for performance IQ; and $\mathrm{F}=1.000, \mathrm{p}=0.369$ for full scale IQ) was not significantly different (table 3 ).

Table 1. Clinical and demographic features of children with Specific Learning Disorder

\begin{tabular}{|c|c|c|}
\hline Demographics & $\mathbf{n}$ & $(\%)$ \\
\hline \multicolumn{3}{|l|}{ Gender } \\
\hline Boys & 468 & 65.4 \\
\hline Girls & 248 & 34.6 \\
\hline \multicolumn{3}{|l|}{ Age groups } \\
\hline Children (6-11 years of age) & 624 & 87.2 \\
\hline Adolescents (12 years of age and above) & 92 & 12.8 \\
\hline Gender versus age groups & Boys & Girls \\
\hline Adolescents (n,\%) & $58(63.0)$ & $34(37.0)$ \\
\hline \multicolumn{3}{|l|}{ Clinical features } \\
\hline \multicolumn{3}{|l|}{ Specific learning disorder diagnosis } \\
\hline First diagnosed ones & 582 & 81.3 \\
\hline Have already diagnosed by SLD & 106 & 14.8 \\
\hline Once diagnosed with mild mental retardation (mild MR) & 28 & 3.9 \\
\hline \multicolumn{3}{|l|}{ Specific learning disorder subtypes } \\
\hline Disorder of written expression & 89 & 12.4 \\
\hline Learning disorder not otherwise specified (LD-NOS) & 78 & 10.9 \\
\hline Mathematics disorder & 36 & 5.0 \\
\hline \multicolumn{3}{|l|}{ Any comorbid psychiatric disorders } \\
\hline None & 419 & 58.5 \\
\hline Borderline intellectual functioning (BIF) (Full Scale of IQ=70-79) & 115 & 16.1 \\
\hline Attention deficit hyperactivity disorder & 103 & 14.4 \\
\hline Anxiety disorders & 36 & 5.0 \\
\hline Communication disorders & 15 & 2.1 \\
\hline Conduct disorder & 12 & 1.7 \\
\hline Elimination disorders & 8 & 1.1 \\
\hline Major depressive disorder & 6 & 0.8 \\
\hline Tic disorders & 2 & 0.3 \\
\hline
\end{tabular}

Table 2. The frequency (n) and percentages (\%) of SLD subtypes according to gender and age groups and their WISC-R sub-scores distribution in their mean and SD terms.

\begin{tabular}{|c|c|c|c|c|c|}
\hline & Reading disorder & $\begin{array}{l}\text { Disorder of written } \\
\text { expression }\end{array}$ & $\begin{array}{l}\text { Learning disorder } \\
\text {-NOS }\end{array}$ & $\begin{array}{l}\text { Mathematics } \\
\text { disorder }\end{array}$ & $\mathbf{p}$ \\
\hline Total $(n=716)$ & $513(71.6)$ & $89(12.4)$ & $78(10.9)$ & $36(5.0)$ & \\
\hline \multicolumn{6}{|l|}{ Gender $[\mathrm{n}(\%)]$} \\
\hline Boys $(n=468)$ & $337(72.0)$ & $60(12.8)$ & $54(11.5)$ & $17(3.6)$ & \multirow{2}{*}{$0.176\left(X^{2}=4.941\right)$} \\
\hline Girls $(n=248)$ & $176(71.0)$ & $29(11.7)$ & $24(9.7)$ & $19(7.7)$ & \\
\hline
\end{tabular}




\begin{tabular}{|c|c|c|c|c|c|c|c|c|c|}
\hline & \multicolumn{2}{|c|}{ Reading disorder } & \multicolumn{2}{|c|}{$\begin{array}{l}\begin{array}{l}\text { Disorder of written } \\
\text { expression }\end{array} \\
\end{array}$} & \multicolumn{2}{|c|}{$\begin{array}{l}\text { Learning disorder } \\
\text {-NOS }\end{array}$} & \multicolumn{2}{|c|}{$\begin{array}{l}\begin{array}{l}\text { Mathematics } \\
\text { disorder }\end{array} \\
\end{array}$} & \multirow[t]{2}{*}{$\mathbf{p}$} \\
\hline \multicolumn{9}{|l|}{ Age groups [n (\%)] } & \\
\hline Children $(n=624)$ & $446(71.5)$ & & $70(11.2)$ & & $78(12.5)$ & & $30(4.8)$ & & $0882\left(\mathrm{X}^{2}=0\right.$ \\
\hline Adolescents ( $\mathrm{n}=92)$ & $67(72.8)$ & & $19(20.7)$ & & $0(0.0)$ & & $6(6.5)$ & & $0.882(X=0.6$ \\
\hline Gender\& age groups & Boys & Girls & Boys & Girls & Boys & Girls & Boys & Girls & \\
\hline Children (n,\%) & $295(72.0)$ & $151(70.6)$ & $47(11.5)$ & $23(10.7)$ & $54(13.2)$ & $24(11.2)$ & $14(3.4)$ & $16(7.5)$ & $0.001 *\left(X^{2}=12.825\right)$ \\
\hline Adolescents (n,\%) & $42(72.4)$ & $25(73.5)$ & $13(22.4)$ & $6(17.6)$ & $0(0.0)$ & $0(0.0)$ & $3(5.2)$ & $3(8.8)$ & $0.098 * *\left(\mathrm{X}^{2}=5.113\right)$ \\
\hline \multicolumn{10}{|c|}{ WISC-R scores [mean (SD)] } \\
\hline VIQ $(n=641)$ & $77.4(12.3)$ & & $78.7(12.9)$ & & $81.4(9.9)$ & & $77.5(12.8$ & & $0.067(\mathrm{~F}=2.401)$ \\
\hline PIQ $(n=641)$ & $89.4(14.1)$ & & $92.1(15.3)$ & & $88.4(11.0)$ & & $92.8(12$. & & $0.187(\mathrm{~F}=1.604)$ \\
\hline FIQ $(n=641)$ & $81.7(12.2)$ & & $84.2(12.5)$ & & $83.7(9.2)$ & & $83.7(11.5$ & & $0.205(\mathrm{~F}=1.534)$ \\
\hline
\end{tabular}

NOS: Not otherwise specified, IQ: Intelligent Quotient, VIQ: Verbal IQ, PIQ: Performance IQ, FIQ: Full-Scale IQ, SD: Standard deviation.

*: Fisher's exact test (significance for male gender, in favor of being reading disorder), **: Fisher's exact test (no significance for female gender)

Table 3. Mean WISC-R sub-scales'IQ scores and its standard deviations (SDs) of patients and their distribution amongst sex and age groups.

\begin{tabular}{|c|c|c|c|c|c|c|c|c|c|}
\hline \multirow[b]{2}{*}{ Gender } & \multicolumn{2}{|c|}{ Reading disorder $(n=513)$} & \multicolumn{2}{|c|}{$\begin{array}{l}\text { Disorder of written } \\
\text { expression }(n=89)\end{array}$} & \multicolumn{2}{|c|}{$\begin{array}{l}\text { Learning disorder }-\mathrm{NOS} \\
(\mathrm{n}=78)\end{array}$} & \multicolumn{2}{|c|}{$\begin{array}{l}\text { Mathematics Disorder } \\
(\mathrm{n}=36)\end{array}$} & \multirow[t]{2}{*}{$\mathbf{p}$} \\
\hline & $\begin{array}{l}\text { Boys }(n=302) \\
\text { pres [mean (SD) }\end{array}$ & Girls $(n=154)$ & Boys $(n=59)$ & Girls $(n=26)$ & Boys $(n=49)$ & Girls $(n=24)$ & Boys $(n=13)$ & Girls $(n=14)$ & \\
\hline V IQ & $78.0(12.0)$ & $76.2(12.8)$ & $77.3(12.5)$ & $81.7(13.4)$ & $80.9(9.7)$ & $82.5(10.5)$ & $81.4(10.6)$ & $74.0(14.0)$ & $\begin{array}{l}0.093 \\
(\mathrm{~F}=2.151)\end{array}$ \\
\hline P IQ & $88.7(14.3)$ & 90.7 (13.9) & $91.6(16.1)$ & $93.3(13.8)$ & $87.3(11.5)$ & 90.7 (9.7) & $94.7(14.6)$ & $91.0(9.4)$ & $\begin{array}{l}0.734 \\
(\mathrm{~F}=0.426)\end{array}$ \\
\hline FIQ & $81.9(11.8)$ & $81.3(12.9)$ & $83.2(12.4)$ & $86.3(12.9)$ & $82.5(8.7)$ & 86.0 (9.9) & $87.0(11.8)$ & $80.7(10.9)$ & $\begin{array}{l}0.203 \\
(\mathrm{~F}=1.540)\end{array}$ \\
\hline $\begin{array}{l}\text { Age } \\
\text { group }\end{array}$ & Child ( $\mathrm{n}=397)$ & $\begin{array}{l}\text { Adolesc } \\
(\mathrm{n}=59)\end{array}$ & Child $(n=67)$ & $\begin{array}{l}\text { Adolesc } \\
(\mathrm{n}=18)\end{array}$ & Child ( $n=73)$ & $\begin{array}{l}\text { Adolesc } \\
(\mathrm{n}=0)\end{array}$ & Child $(n=22)$ & $\begin{array}{l}\text { Adolesc } \\
(\mathrm{n}=5)\end{array}$ & \\
\hline \multicolumn{10}{|c|}{ WISC-R scores [mean (SD)] } \\
\hline VIQ & $78.6(12.1)$ & $69.3(10.7)$ & $79.2(13.2)$ & $76.8(11.6)$ & $81.4(9.9)$ & $0(0.0)$ & $79.3(12.6)$ & $69.8(11.8)$ & $\begin{array}{l}0.144 \\
(\mathrm{~F}=1.945)\end{array}$ \\
\hline PIQ & $89.3(14.4)$ & $89.6(12.6)$ & $92.6(15.5)$ & $90.4(15.0)$ & $88.4(11.0)$ & $0(0.0)$ & $93.4(13.2)$ & $90.4(5.5)$ & $\begin{array}{l}0.778 \\
(F=0.251)\end{array}$ \\
\hline F IQ & $82.5(12.0)$ & $76.4(11.7)$ & $84.4(13.2)$ & $83.2(9.8)$ & $83.7(9.2)$ & $0(0.0)$ & $85.0(12.1)$ & $78.4(6.9)$ & $\begin{array}{l}0.369 \\
(\mathrm{~F}=1.000)\end{array}$ \\
\hline
\end{tabular}

NOS: Not otherwise specified, B: Boys, G: Girls, IQ: Intelligent Quotient, VIQ: Verbal IQ, PIQ: Performance IQ, FIQ: Full-Scale IQ, SD: Standard deviation, Child: Children (6-11 years of age), Adolesc: Adolescents (12 years of age and above).

Evaluating of discrepancy rates of WISC-R subscale scores (VIQ>PIQ or PIQ>VIQ) did not reveal any significant pattern for SLD subtypes. Also there were not any consistent discrepancy patterns (VIQ>PIQ or PIQ>VIQ) in SLD subtypes (table 4).
Only significance found in this study was the presence of ADHD in children with "reading disorder". It was statistically related with each other $\left(\mathrm{X}^{2}=7.006, \mathrm{p}=0.008\right)$ " while other subtypes of SLD were not (table 5).

Table 4. The frequency ( $n$ ) and percentage (\%) distribution of discrepancy rates of subjects with SLD.

\begin{tabular}{|c|c|c|c|c|c|}
\hline & Reading disorder $(n=513)$ & $\begin{array}{l}\text { Disorder of written expression } \\
(\mathrm{n}=89)\end{array}$ & $\begin{array}{l}\text { Learning disorder } \\
\text {-NOS }(n=78)\end{array}$ & $\begin{array}{l}\text { Mathematics } \\
\text { Disorder }(n=36)\end{array}$ & $\mathbf{p}$ \\
\hline \multicolumn{6}{|c|}{ Discrepancy } \\
\hline \multicolumn{6}{|c|}{ VIQ $>$ PIQ [n(\%)] } \\
\hline Yes & $86(18.9)$ & $16(18.8)$ & $19(20.6)$ & $5(18.5)$ & \multirow{2}{*}{$0.328\left(X^{2}=6.919\right)$} \\
\hline No & $365(80.4)$ & $69(81.2)$ & $52(71.2)$ & $22(81.5)$ & \\
\hline \multicolumn{6}{|c|}{ PIQ > VIQ [n(\%)] } \\
\hline Yes & $355(78.2)$ & $67(78.8)$ & $51(69.9)$ & $22(81.5)$ & \multirow{2}{*}{$0.470\left(X^{2}=5.599\right)$} \\
\hline No & $95(20.9)$ & $18(21.1)$ & $20(27.4)$ & $5(18.5)$ & \\
\hline
\end{tabular}

RD: Reading disorder, DRE: Disorder of written expression, LD-NOS: Learning disorder-Not otherwised specified, MD: Mathematics, IQ: Intelligent Quotient, VIQ: Verbal IQ, PIQ: Performance IQ

Table 5. The presence of $A D H D$ and its relation with SL subtypes.

\begin{tabular}{llll}
\hline Specific learning disorder subtypes & ADHD Yes (n=103) & ADHD No (n=613) & p \\
\hline Reading disorder & 85 & 428 & $0.008\left(\mathrm{X}^{2}=7.006\right)$ \\
Disorder of written expression & 14 & 75 & $0.699\left(\mathrm{X}^{2}=0.149\right)$ \\
Mathematics disorder & 4 & 32 & $0.566\left(\mathrm{X}^{2}=0.330\right)$ \\
Learning disorder not otherwise specified (LD-NOS) & 0 & 78 & - \\
\hline
\end{tabular}




\section{Discussion}

This study aimed to evaluate of demographics and clinical features of child or adolescents with SLD and to determine if there was any relation between SLD and WISC-R patterns. SLD affects around $2-10 \%$ of the school-age population [1], which this rate was found as $2.9 \%$ in this study. The number of boys with SLD was almost twice as high as that the number of girls. Sex differences in SLD are estimated to be at around 1.5-2.1 in favor of males [2] which consistent with this result. As far as concerned the age factor, SLD seen in under 12 years of age group was found nearly 7 times as high as that for adolescents.

Amongst the SLD subtypes, the "reading disorder" constituted a major form of SLD found (71.6\% of all). Reading disorder (RD) in the most common type of SLD in whom children receive special education services [2]. It has been previously shown that there is no longer a greater prevalence of RD in boys [4], which is estimated to be at about 1.5-2.1 in favor of males. In this recent study, boys/girls ratio was $1.9(337 / 176)$, consisted with this information, though within the gender analysis, being male was found as significant for "reading disorder $\left(p=0.001, X^{2}=12.825\right)$, whereas there was no significance between being female and any type of SLD.

The second frequent type of SLD found in this study was "disorder of written expression (12.4\%)". This subtype of SLD, in this study, was twice higher in boys than that of girls (60/29). In another study, conducted by Rodriguez et al. [7], writing learning disability rate was shown as 4 times higher in boys (male/female ratio: 80/19).

In this recent study, the "mathematics disorder" type was the least found SLD type (5\%). In one study, the $6.6 \%$ of arithmetic skills was reported in both an urban and a rural population of school children [8].

There was no difference between SLD subtypes and gender. Similar to this result has been reported by Moll et al. [9], as no gender differences were observed for reading problems or all other three learning disorders. Also, distribution of SLD subtypes amongst age groups was found as similar.

As far as WISC-R patterns are concerned, any type of SLD did not differ significantly in mean verbal or performance IQ scores, as well as mean full scale IQ scores terms. In contrast to this result, Soysal et al. [10] reported in their 40 of SLD samples, there was a predictive value of verbal IQ scores for SLD, without analyzing with its subtypes, consistent with the report of D'Angiulli and Siegel [11], which pointed out that the "reading disorder's both verbal and performance IQ scores has been found significantly lower than that of "mathematics disorder". Although in both studies, the verbal subtest scores (vocabulary, similarities, comprehension, information, arithmetic, digit span) and performance subtest scores (block design, object assembly, picture completion, picture arrangement, coding, mazes) of WISC-R test have been analyzed, their findings differed. In the former, conducted by Soysal et al., only block design and picture arrangement variables were found as related with SLD without analyzing any subtype of it [10], whereas in the latter, only in "reading disorder", block design and picture completion subtests were significantly lower than that of "mathematics disorder" [11]. In addition to these two studies, Coplin and Morgan [12] and Sattler [13] have also showed in their studies that verbal scores were found significantly lower than performance scores in children with SLD. Lately published study, Moura et al., lately reported that WISC-R subtests evaluating verbal abilities, processing speed and working memory came in some useful information in children with developmental dyslexia (DD) [14].

Another similar result was found in analyzing all mean IQ scores' distribution (verbal IQ, performance IQ and full scale IQ) within the subtypes of SLD and theirs relation either sex or age groups. There was no difference between the IQ scores and being boys or girls, or being children or adolescents.

Evaluating of discrepancy rates of WISC-R subscale scores (VIQ>PIQ or PIQ>VIQ) did not reveal any significant pattern for SLD subtypes. Also there were not any consistent discrepancy patterns (VIQ>PIQ or PIQ>VIQ) in SLD subtypes. These results are consistent with D'Anguilli and Siegel [11] and Kaufman [15]. In the former study, the verbal-performance discrepancy patterns were not consistently found in children with SLD. In the latter, Kaufman pointed out significant verbal-performance discrepancies in children who have not any SLD and children with SLD without showing these discrepancies [15]. Although we did not analyze the verbal subtest scores (vocabulary, similarities, comprehension, information, arithmetic, digit span) and performance subtest scores (block design, object assembly, picture completion, picture arrangement, coding, mazes) in this study, this verbal-performance discrepancy results might be inferred that they are not specific for any learning disorder subtypes. In literature, a similar result with this has once been reported by D'Anguilli and Siegel [11]. It would appear then that analyzing of WISC-R patterns to evaluate or even diagnose is not accurate or might not come in useful. However, recent studies evaluating of WISC-IV test (fourth edition), not WISC-R, in different disabilities such as SLD and intellectual disabilities, have reported some conclusion. For instance, Cornoldi et al. [16] reported that WISC-IV test (four-domain scores: verbal comprehension, perceptual reasoning, working memory, processing speed) could be used in children with SLD from differentiating intellectual disabilities via using the "General Abilities Index (GAI), which is calculated using only the verbal comprehension and perceptual reasoning scores obtained from WISC-IV test. Similar with this conclusion, Poletti has pointed out the GAI obtained from WISC-IV test was the best measure to identify intellectual functioning in children with SLD [17]. In another report supporting this idea was conducted by Koriakin et al. [18] and they showed that higher GAI scores of WISC-IV could be used for discriminating of subjects with SLD than those who had intellectual disability. Likewise, Styck and Watkins [19] reported that four-domain 
scores was found as consistent with their bi-factorial model a general intelligence breadth factor in children with SLD. Given this information, further studies using by WISC-IV test could very well be using in SLD subtypes and its relation between other neurodevelopmental disorders like intellectual disability.

In terms of the comorbidity rates, there was more than half of children with SLD had no any comorbid psychiatric disorders. In the rest of the sample (42.5\%) "borderline intellectual functioning (BIF)" was the most frequent disorder (16.1\%) accompanying by SLD. There was not clear information regarding the frequency of BIF in children with SLD, though its prevalence in child population comprise at a minor fraction (10-15\%) [20]. In this study, "BIF" accepted as that full scale of IQ scores obtained from WISC-R test is 70-79. Although there is still different range of its determination which is which, differs from study to study, as IQ range is $70-85[16,20-23]$, we determined its range as 70-79 of the full scale IQ because DSM-IV-TR defined the "intellectual disability" as a standard score of 70 on an administered measure of cognitive functioning [18, 24],

BIF perhaps one of the disorders rarely attracts clinicians or researchers' attention [25]. It could very well cause malfunctions in daily life abilities, and negative adverse events $[23,25]$. In the SLD context, it has been shown that BIF has been found directly associated with behavior problems and student absenteeism in both sexes who had "reading disorder" $[22,26]$.

In recent study, ADHD was second frequent disorder found in children with SLD, which more than a tenth of children $(14.4 \%)$ with SLD had also ADHD. ADHD is probably by the most studied disorder in SLD. Lately, Margari et al. [27] reported in their study of the comorbidity rates of SLD at a $62.2 \%$ rate in children with SLD, which the most frequent comorbid disorder was ADHD (33\% of all SLD cases). In another study, the ADHD-SLD comorbidity has been reported at $45.1 \%$ from reviewing of total 17 studies (2001-2011 years) [28]. Karende et al., [29] also shown ADHD comorbidity at a $20 \%$ rate in children with SLD. Our lower ADHD comorbidity rates compared with these studies, it might be stemming mainly from our study's cohort cross-sectional nature.

In this study, the presence of ADHD was found statistically related with "reading disorder". The link between reading disorder and ADHD is well-established previously [30-32]. This relation could very well affect each other's course than patients without these disorders. In this context, further studies evaluating of this relation and its longitudinal course would come in useful both to evaluate and to treat the both disorders.

Another comorbid psychiatric disorder detected in children with SLD was anxiety disorders, and one out of 20 of children had any type of them (5\%). In one study, conducted by Margari et al. [27], anxiety disorder has been reported at a $28.8 \%$ rate in children with SLD. Chiappedi and Baschenis [33] reported increased anxiety in their cases with SLD and showed a significant negative correlation between a school experience perceived as positive and anxiety. The role of school experience for children with SLD seems highly relevant also for their psychological well-being.

Limitations of this study, firstly was that because of its cohort cross-sectional clinical sampling nature, these findings could not be generalized to the population. Further research would make clear the relation between cognitive measurements by using a number of intelligence scales and SLD. WISC-IV test, might well be used for determining and evaluating of SLD. Also, further studies evaluating of relation between ADHD and SLD in neurodevelopmental terms would come in useful both to evaluate and to treat the both disorders.

\section{References}

[1] L. Margari, M. Buttiglione, F. Craig, A. Cristella, C. De Giambattista, E. Matera, F. Operto and M. Simone, "Neuropsychopathological comorbidities in learning disorders," BioMedCentral Neurology, vol. 13, pp. 198, 2013.

[2] K. Pierce, "Developmental disorders of learning, communication, and motor skills," in Dulcan's Textbook of Child and Adolescent Psychiatry, M.K. Dulcan, Ed. APA Inc Press, pp: 1st ed., pp. 191-197, 2010.

[3] A. San Martin and M.R. Pagani, "Understanding intellectual disability through RASopathies". J Physiol Paris, pii: S0928-4257(14)00020-5.doi:10.1016/j.jphysparis.2014.05.003, 2014.

[4] M. Rutter, A. Caspi A and D. Fergusson et al., "Sex differences in developmental reading disabilitiy: new findings from four epidemiological studies," JAMA, vol. 291, pp. 2007-2012, 2004.

[5] V. Zakopoulou, V. Mavreas, P. Christodoulides, A. Lavidas et al., "Specific learning difficulties: A retrospective study of their co morbidity and continuity as early indicators of mental disorders," Res Dev Disabil, vol. 35, pp. 3496-3507, 2014.

[6] American Psychiatric Association, Diagnostic and statistical manual of mental disorders $\left(4^{\text {th }}\right.$ ed., text rev.), Washington, DC, 2000 .

[7] C. Rodríguez, P. González-Castro, R. Cerezo and David Álvarez, "Attention deficit hyperactivity disorder (ADHD) and writing learning disabilities," in Learning Disabilities, W. Sittiprapaporn (Ed.), InTech Press, pp.49-66, 2012.

[8] J. Hein J, M.W. Bzufka, K. J. Neumärker, "The specific disorder of arithmetic skills. Prevalence studies in a rural and an urban population sample and their clinico-neuropsychological validation," Eur Child Adolesc Psychiatry, vol. 9 Suppl 2, pp. II87-101, 2000.

[9] K. Moll, S. Kunze, N. Neuhoff, J. Brude J and G. Schulte-Körne, "Specific learning disorder: prevalence and gender differences,” PLoS One, vol. 29, pp. e103537, 2014.

[10] A.S. Soysal, A. I. Kockar, E. Erdogan, S. Senol and K. Gucuyener, "Evaluation of WISC-R profiles in children with learning disorders," Clinical Psychiatry, vol. 4, pp. 225-231, 2001.

[11] A. D'Angiulli and L. S. Siegel, "Cognitive functioning as measured by the WISCR: Do children with learning disabilities have distinctive patterns of performance?" Journal of Learning Disabilities, vol. 36, pp. 48-58, 2003. 
[12] J.W. Coplin and S. B. Morgan, "Learning disabilities: a multidimensional perspective" J Learning Disabilities, vol. 21, pp. 614-622, 1988.

[13] J.M. Sattler, "Assessment of learning disabilities, attention deficit-hyperactivity disorder, conduct disorder, pervasive developmental disorder, and sensory impairments," in Assessment of children. Inc. San Diego, pp. 597-645, 1998.

[14] O. Moura, M. R. Simões and M. Pereira, "WISC-III cognitive profiles in children with developmental dyslexia: specific cognitive disability and diagnostic utility," Dyslexia, vol. 20, pp. 19-37, 2014.

[15] A. Kaufman, "Intelligent testing with the WISC-R-III". New York: Wiley, 1994.

[16] C. Cornoldi, D. Giofrè, A. Orsini and L. Pezzuti, "Differences in the intellectual profile of children with intellectual vs. learning disability," Res Dev Disabil, vol. 35, pp. 2224-2230, 2014.

[17] M. Poletti, "WISC-IV Intellectual Profiles in Italian Children With Specific Learning Disorder and Related Impairments in Reading, Written Expression, and Mathematics," J Learn Disabil, pii: 0022219414555416, 2014.

[18] T. Koriakin, M. D. Mccurdy, A. Papazoglou, A. E. Pritchard et al., "Classification of intellectual disability using the Weschler Intelligence Scale for children: full scale or general abilities index?" Dev Med Child Neurol, vol. 55, pp. 840-845, 2013.

[19] K. M. Styck and M. W. Watkins, "Structural Validity of the WISC-IV for Students With Learning Disabilities," J Learn Disabil, pii: 0022219414539565, 2014.

[20] E. Emerson, S. Einfeld and R. J. Stancliffe, "The mental health of young children with intellectual disabilities or borderline intellectual functioning," Soc Psychiatry Psychiatr Epidemiol, vol. 45 , pp. $579-587,2010$.

[21] F. Baglio, M. Cabinio, C. Ricci, G. Baglio, S. Lipari, L. Griffanti et al., "Abnormal development of sensory-motor, visual temporal and parahippocampal cortex in children with learning disabilities and borderline intellectual functioning," Front Hum Neurosci, vol. 8, pp. 806, 2014.

[22] L. Salvador-Carulla, J. C. García-Gutiérrez, M. R. Gutiérrez-Colosía et al., "Borderline intellectual functioning: consensus and good practice guidelines," Rev Psiquiatr Salud Ment, vol. 6, pp. 109-120, 2013.

[23] S. Karande, S. Kanchan and M. Kulkarni, "Clinical and psychoeducational profile of children with borderline intellectual functioning," Indian J Pediatr, vol. 75, pp. 795-800, 2008.

[24] American Psychiatric Association. Diagnostic and Statistical Manual of Mental Disorders Text revision. 4th edition. Washington, DC, USA: American Psychiatric Association, 2000 .

[25] E. Fernell and U. Ek, "Borderline intellectual functioning in children and adolescents - insufficiently recognized difficulties," Acta Paediatr, vol. 99, pp. 748-753, 2010.

[26] D. Farrington, "Psychosocial predictors of adult antisocial personality and adult convictions," Behav Sci Law, vol. 5, pp. 605-622, 2000.

[27] L. Margari, M. Buttiglione, F. Craig, A. Cristella, C. De Giambattista, E. Matera, F. Operto and M. Simone, "Neuropsychopathological comorbidities in learning disorders," BMC Neurol, vol. 13, pp.198, 2013.

[28] G. J. DuPaul, M. J. Gormley and S. D. Laracy, "Comorbidity of LD and ADHD: implications of DSM-5 for assessment and treatment," Journal of Learning Disabilities, vol. 46, pp. 43-51, 2013.

[29] S. Karande, N. Satam, M. Kulkarni, R. Sholapurwal, A. Chitre and N. Shah, "Clinical and psychoeducational profile of children with specific learning disability and co-occurring attention-deficit hyperactivity disorder," Indian J Med Sci, vol. 61, pp. 639-647, 2007.

[30] S. Hinshaw, "Externalizing behaviour problems and academic underachievement in childhood and adolescents: causal relationship and underlying mechanisms," Psychol Bull, vol. 1111, pp. 127-155, 1992

[31] E. G. Willcutt, R. S. Betjemann, L. M. McGrath, N. A. Chhabildas NA, R. K. Olson et al., "Etiology and neuropsychology of comorbidity between RD and ADHD: the case for multiple-deficit models," Cortex, vol. 46, pp. $1345-1361,2010$

[32] E. G. Willcutt, B. F. Pennington and J. C. DeFries, "Twin study of the etiology of comorbidity between reading disability and attention-deficit/hyperactivity disorder," Am J Med Genet, vol. 96, pp. 293-301, 2000.

[33] M. Chiappedi and I. M. Baschenis, "Specific learning disorders and anxiety: a matter of school experience?" Minerva Pediatr, 2014 Sep 22. [Epub ahead of print] 